\title{
A Virtual Community Pharmacy Advanced Pharmacy Practice Experience (APPE) in Response to COVID-19
}

\author{
Robin Moorman-Li ${ }^{1}$, Eric F. Egelund ${ }^{1}$, Jessica Reid ${ }^{1}$, Carol A. Motycka ${ }^{1}$, Ashlan Kunz Coyne ${ }^{2}$, Eric Jakab ${ }^{1}$, \\ Kimberly Stultz ${ }^{2}$, Shauna Buring ${ }^{3} \&$ Stacy Miller, \\ ${ }^{1}$ Department of Pharmacotherapy and Translational Research, College of Pharmacy, University of Florida, 580 W. $8^{\text {th }}$ \\ Street, Jacksonville, FL 32209, USA \\ ${ }^{2}$ Department of Pharmacy, University of Florida Health Jacksonville, 655 W. $8^{\text {th }}$ Street, Jacksonville, FL 32209, \\ USA \\ ${ }^{3}$ Department of Pharmacotherapy and Translational Research, College of Pharmacy, HPNP Building, Gainesville, FL \\ 32610-0484, USA
}

${ }^{*}$ Correspondence: College of Pharmacy, University of Florida, Gainesville, FL., 32610, USA. Tel: 352-273-7820.

E-mail: stacy.miller@cop.ufl.edu

Received: September 11, 2020

Accepted: November 4, 2020 Online Published: November 17, 2020

doi:10.5430/jct.v9n4p89

URL: https://doi.org/10.5430/jct.v9n4p89

\begin{abstract}
The response to COVID-19 created a need to evaluate options and develop innovative solutions to assure students progressed towards graduation. Creating both a Community Pharmacy APPE Test-Out Option and a Virtual Community Pharmacy APPE was a positive experience which provided a vital resource for students who were unable to complete the traditional Community Pharmacy APPE due to the pandemic. This solution provided a unique opportunity to utilize the combined expertise of faculty to tailor the Community Pharmacy APPE based on the individual student's previous experience and educational needs and meet both ACPE and graduation requirements. Further development of this option could prove useful as we move forward in these unprecedented times.
\end{abstract}

Keywords: COVID-19, APPE, community pharmacy, distance learning

\section{Introduction}

The COVID-19 pandemic has impacted numerous communities, disrupting the home and work environments of millions of individuals across the United States, including students enrolled in colleges and universities. College curriculums across the nation were forced to transition to completely online instruction within a very short time frame for all didactic learning experiences, and many in the experiential settings in order to reduce the risk of transmission, ensure student safety and preserve resources (Fuller et al., 2020). Certain learning experiences transition to virtual environments easier than others.

Advanced Pharmacy Practice Experiences (APPEs) are designed to integrate students into the workplace environment and to gain professional experience and competence in a clinical setting under the supervision of a preceptor, usually a licensed pharmacist.

The Accreditation Council for Pharmacy Education (ACPE) requires at least 1,440 hours of APPEs to be completed in order for students to graduate (Accreditation Council for Pharmacy Education Self-Assessment Instrument for the Professional Degree Program of Colleges and Schools of Pharmacy, 2016). In addition, 160 hours are required in each of the four required APPE areas ((1) community pharmacy; (2) ambulatory patient care; (3) hospital/health system pharmacy; and (4) inpatient general medicine patient care) with the majority of APPEs focused on patient care (Fuller et al., 2020). The current curriculum at the University of Florida College of Pharmacy requires 1,680 hours of APPEs with each APPE scheduled for a total of 240 hours. This allowed for the formation of a test-out option for the Community APPE where students who had already met certain requirements, such as community pharmacy experience and completion of the required number of hours through other APPE rotations for graduation. However, with many APPE sites unable to bring students into their practice setting due to the COVID-19 pandemic, some 
students were at risk for not meeting ACPE requirements to graduate on time. Therefore, a Virtual Community Pharmacy APPE was also designed to meet ACPE requirements.

\section{Methods}

Initial review of all fourth-year students identified 34 students who had yet to complete a Community Pharmacy APPE to meet graduation requirements. Multiple community rotation sites agreed to host the students who were in need of a new community APPE site. Even so, some students were unable to complete the community APPE rotation on-site in a community pharmacy due to extenuating circumstances associated with COVID-19. Strict eligibility requirements were developed to identify students who were unable to complete an on-site community APPE rotation. These criteria included but were not limited to: unavailability of a community APPE site in the students' vicinity, and health-related concerns surrounding exposure to COVID-19 during an on-site rotation. Students who were scheduled for a community rotation were eligible to test-out of their Community APPE if they met the following requirements: 1) had significant work experience-defined by the college as working at least 500 hours in a community pharmacy while enrolled as a pharmacy student, and 2) had already met the curriculum requirements of 1,680 hours of APPE experience (Accreditation Council for Pharmacy Education Self-Assessment Instrument for the Professional Degree Program of Colleges and Schools of Pharmacy, 2016). Students who were unable to be on-site for her or his scheduled community rotation, who did not have at least 500 hours working in a community pharmacy, and had not yet met the curricular requirement of 1,680 APPE hours, were enrolled in a virtual community APPE experience.

\subsection{Community Pharmacy APPE Test-Out Option}

Table 1. Requisite Topics for Community Pharmacy APPE Test-Out

\begin{tabular}{ll}
\hline \multicolumn{1}{c}{ Topic } & \multicolumn{1}{c}{ Comments } \\
\hline Errors \& Omissions & 10 prescriptions with commonly encountered errors. Students were \\
& required to identify the errors or omissions and explain what proper steps \\
& would need to be taken to rectify the problem \\
& Common calculation problems encountered in Community Practice: \\
- Liquid dispensing & - Metered-dose inhalers \\
& - Insulin quantities \\
& - Weight-based Dosing \\
& - Opioid equianalgesic Calculations \\
& Drug information question: \\
& - Medical marijuana drug interaction with patient's prescriptions \\
& - Goldenseal (an herbal remedy) for masking illicit substances in drug \\
& testing for the workplace \\
& - Diversity \& Inclusion, Biases \\
& - Inventory management \\
& - Negative comments from patients \\
& - Controlled substance laws \\
& - PDMP regulations and proper evaluation of provided reports (E-FORCSE, \\
Pharmacy Management & 2020), (Florida Prescription Drug Monitoring Program AwARxE Requestor User Support Manual, 2018) \\
& - Narcan counseling \\
- Role play: Common self-care cases: students were evaluated on proper & - Pseudoephedrine dispensing laws \\
Opioid considerations in Community & - Substance abuse case scenario discussion including locating proper \\
Practice/PDMP & educational documents for patients \\
\hline Self-Care &
\end{tabular}

PDMP: Prescription drug monitoring program 
Table 2. Virtual Community Pharmacy APPE Weekly Schedule

\begin{tabular}{|c|c|c|}
\hline Week & Topics & Assignments \\
\hline 1 & $\begin{array}{l}\text { 1. Overview of Community } \\
\text { Pharmacy } \\
\text { 2. Professionalism } \\
\text { 3. Diabetes } \\
\text { 4. Longitudinal DI: } \\
\text { COVID-19 }\end{array}$ & $\begin{array}{l}\text { A1: Complete CORE Readiness Community Overview Modules } \\
\text { A2: Complete CEImpact Module: PPCP } \\
\text { B1: Watch CORE - Professionalism Videos } \\
\text { C1: Create Chart: Diabetes Drug Comparison } \\
\text { C2: Drug information question: GLP-1 agonists and thyroid cancer } \\
\text { C3: Present Patient Case of choice including counseling on medical device } \\
\text { D1: COVID DI meetings each Wednesday and Friday (1 hour meetings) }\end{array}$ \\
\hline 2 & $\begin{array}{l}\text { 1. Pharmacy Management } \\
\text { 2. Hypertension } \\
\text { 3. COVID-19 } \\
\text { 4. *Longitudinal DI: } \\
\text { COVID-19 }\end{array}$ & $\begin{array}{l}\text { A1. Read Effective Pharmacy Management } \\
\text { A2: Watch: The Muse: Workplace Diversity } \\
\text { A3: Assignment: Develop management plan } \\
\text { B1: Create Chart: Hypertension Drug Comparison } \\
\text { B2: Complete Drug Utilization Review Project } \\
\text { B3: Present Patient Case of choice including use of a self-care product } \\
\text { C1: Watch CEImpact: COVID-19 Guidelines } \\
\text { C2: Watch CEImpact: COVID-19 live presentation on Evidence Based } \\
\text { Treatment } \\
\text { D1: COVID DI meetings each Wednesday and Friday (1 hour meetings) }\end{array}$ \\
\hline 3 & $\begin{array}{l}\text { 1. Immunizations } \\
\text { 2. Hyperlipidemia } \\
\text { 3. COVID-19 } \\
\text { 4. *Longitudinal DI: } \\
\text { COVID-19 }\end{array}$ & $\begin{array}{l}\text { A1: Watch CEImpact: Vaccine Advocates } \\
\text { A2: Watch CEImpact: Disrupting the Vaccine Industry (Zoster) } \\
\text { A3: Watch CEImpact: Decisions, Decision (PCV13) } \\
\text { B1: Create Chart: Hyperlipidemia Drug Comparison } \\
\text { B2: Present patient case: Hyperlipidemia or Immunization } \\
\text { C1: COVID-19 Journal Club } \\
\text { D1: COVID DI meetings each Wednesday and Friday (1 hour meetings) }\end{array}$ \\
\hline 4 & $\begin{array}{l}\text { 1. Prescription Verification } \\
\text { Process } \\
\text { 2. Legal Topics } \\
\text { 3. Pregnancy Topics } \\
\text { 4. Pain Management } \\
\text { 5. *Longitudinal DI: } \\
\text { COVID-19 }\end{array}$ & $\begin{array}{l}\text { A1: Watch CEImpact: Calculations Review } \\
\text { A2: Watch CEImpact: Prescription Checking Process } \\
\text { A3: Complete Errors and Omission Scenarios } \\
\text { B1: Legal Topics: Summarize records retention, required elements of } \\
\text { prescriptions and PDMP } \\
\text { C1: Create Chart: OTC medications in pregnancy } \\
\text { D1: Create Chart: Pain Management Drug Comparison } \\
\text { E1: COVID DI meetings each Wednesday and Friday (1 hour meetings) }\end{array}$ \\
\hline 5 & $\begin{array}{l}\text { 1. Medication Safety } \\
\text { 2. Ethics } \\
\text { 3. Psychiatry } \\
\text { 4. *Longitudinal DI: } \\
\text { COVID-19 }\end{array}$ & $\begin{array}{l}\text { A1: Watch CEImpact: Making it Real (Safety Simulation) } \\
\text { A2: MedWatch Activity } \\
\text { B1: Ethics discussion: Inappropriate prescribing practices } \\
\text { B2: Create Quality Improvement Plan } \\
\text { C1: Create Chart: Psychiatric Drug Comparison } \\
\text { C2: Drug Utilization Review } \\
\text { C3: Patient Case Presentation: Include cultural sensitivity including } \\
\text { discussion from provided Youtube discussion } \\
\text { D1: COVID DI meetings each Wednesday and Friday (1 hour meetings) }\end{array}$ \\
\hline 6 & $\begin{array}{l}\text { 1. Self Care } \\
\text { 2. Pulmonary } \\
\text { 3. Final Presentation: Topic of } \\
\text { Choice } \\
\text { 4. * Longitudinal DI: } \\
\text { COVID-19 }\end{array}$ & $\begin{array}{l}\text { A1: Create Self-Care Chart: GI, Allergies, Cold \& Cough } \\
\text { A2: Create Pediatric OTC chart: GI, Allergies, Cold \& Cough, Pain } \\
\text { A3: Role Play: Self Care Scenarios: GI, Allergies, Cold \& Cough, Pain } \\
\text { B1: Create Chart: Pulmonary Drug Comparison: COPD \& Asthma } \\
\text { C1: Final Presentations: COVID-19 Testing Devices, COVID-19 treatment } \\
\text { options } \\
\text { D1: COVID DI meetings each Wednesday and Friday (1 hour meetings) }\end{array}$ \\
\hline
\end{tabular}

*NOTE: Longitudinal COVID-19 Drug Information Program: Twice weekly drug information meetings/presentations/projects focused on Covid-19. This experience was an additional requirement under separate faculty guidance and instruction. Successful completion required for completion of Virtual Community Pharmacy APPE. 
Development of the Community Pharmacy APPE test-out process began with a faculty-led brainstorming session composed of individuals with community pharmacy experience to identify core topics and skills required to competently practice in a community pharmacy setting. These core topics and skills would be covered and assessed by the faculty with expertise in the community pharmacy setting using a variety of methods. Upon receiving approval for consideration for the test-out process, assignments were provided to the students one week prior to the virtual test-out date (Table 1). Faculty member responsibilities in the test-out process included virtually meeting with students to review assignments, assess student knowledge, practice core topics and skills, and role-play patient care simulations. Faculty provided both verbal and written feedback to students and the course coordinator following the completion of the test-out process. Students were graded on an unsatisfactory/needs improvement/satisfactory scale based on the faculty feedback.

\subsection{Virtual Community Pharmacy APPE Rotation}

Development of the Virtual Community Pharmacy APPE required a coordinated approach by faculty members with a variety of practice interests and experience in multiple practice settings, both community and otherwise. Learning objectives were aligned with the traditional Community Pharmacy APPE required course level objectives. To achieve this goal, a broad variety of weekly discussion topics completed through Zoom meetings were chosen to offer a review of topics pertinent to practicing as a competent community pharmacist (Table 2). Faculty selected discussion topics based on experience and specialized interest to ensure a rich in-depth topic discussion. The following subjects were considered essential to a Virtual Community Pharmacy APPE: pharmacy management, professionalism, self-care, opioid conversion, prescription drug monitoring program (PDMP), vaccinations, and specific disease states with high morbidity in the U.S. (hyperlipidemia, diabetes, hypertension). Completion of drug information questions relevant to community pharmacy, participation in a longitudinal COVID-19 drug information program, and a contribution to published online educational resources such as fact sheets related to pharmacists' questions about COVID-19 were also required (University of Florida, 2020). Modules from CEImpact were used to supplement student exposure to selected topics and offered specific educational points to augment the faculty topic discussion (CEImpact, 2020). Videos as well as reading assignments were assigned in each of these modules to further support virtual learning and engagement. Students were asked to give a brief presentation of the assigned topic(s) and follow up with specific questions developed by the faculty.

Due to the possibility that additional students would need to halt their on-site rotations because of illness, quarantine, or logistical issues, this course was designed for flexible teaching in the instance a student was required to quarantine and needed supplemental learning to meet graduation requirements for their Community APPE. For example, a student may enter into in the virtual APPE mid-week in the rotation if they were asked to quarantine and could then exit the virtual APPE and return to their on-site community pharmacy rotation as appropriate.

\section{Results}

The number of students participating in the virtual APPE experience was fluid, given the nature of the need to enter the virtual rotation or return to community practice, and based on various factors including quarantine stipulations, clinical site recommendations, and faculty or student circumstances. Initially, one student enrolled in the virtual APPE and three students applied for the test-out option. Two additional students then transitioned into the virtual APPE during the six-week long block. One of these students enrolled in week 2 and completed the APPE virtually. The second student enrolled in week 3 and completed two weeks of virtual APPE while in quarantine and then was able to return to the APPE practice site. Ultimately, three students met criteria for the test-out option while one student completed the full 6-week virtual APPE and two students partially participated in the virtual APPE.

\section{Discussion}

Student practice in the community pharmacy setting became limited for some due to the COVID-19 pandemic and required a virtual option to be developed. Previous studies have demonstrated success using video conferencing and online modalities in APPE delivery (Eiland et al., 2018). Other institutions and other pharmacy practice settings have described their transition to online experiential platforms with direct daily videoconference interactions which substituted for the direct daily face-to-face interactions that would have otherwise been assessed during an APPE rotation outside of a pandemic situation (Badreldin et al., 2020). Similarly, topic discussions, drug information questions, and reviewing COVID-19 updates appeared in other virtual APPEs while a common drawback was the absence of direct patient care and additional interprofessional healthcare provider interaction (Badreldin et al., 2020), 
(Mohammad et al., 2020).

The major limitation of the Virtual Community Pharmacy APPE is the lack of live, "real-time" participation in community pharmacy activities. This was important to us as we wished to emulate the experience of community pharmacy as closely as possible, yet we were reminded that students had completed the required IPPE training in a community pharmacy between their first and second year. However, significant attempts were made to mimic certain aspects of the community pharmacy experience. For example, time restraints were introduced for the drug information questions. Specific training on inventory management and prescription verification was simulated by a practicing community pharmacist in real time. Metered-dose inhaler, proper glucometer use, and vaccine administration techniques were reviewed through additional training in detail, then students were required to demonstrate the proper technique they learned using household items. Lastly, students were asked to simulate reporting a medication error by completing the required steps, including the completion of a medication error reporting form.

Constructive criticism of the course was collected and the overall feedback which was provided regarding the experience was very positive. There were, however, some suggestions that were given in regards to improvement which we felt could be added to future renditions of the course. First, students felt one addition to the course which would benefit their experience would be to include a module on addressing "difficult conversations" with a patient. This could be completed through a recorded video or real time interaction with faculty. Another addition to the course which would benefit students would be to include a module reviewing the medication ordering process as well as the process for checking-in medications once delivered. These two processes would aid students in reviewing the business skills needed on a daily basis in community pharmacy practice. Other potential worthwhile activities may include additional real time demonstrations of additional testing and training supplies that are often used in a community pharmacy. These supplies, which could include inhalers, spacers, and diabetic testing supplies, could be mailed to students and allow for real time demonstrations between the students and faculty.

\section{Conclusion}

Amidst a pandemic, online options were sought for fourth-year pharmacy students to complete their APPE requirements. Creating both a Test-Out option and a Virtual Community APPE that met ACPE requirements for students to graduate was of utmost importance. Faculty collaboration was necessary to ensure students gained insight into the many aspects of a community pharmacy APPE in an online format. The creation of these two modalities ensured students completed their degree requirements and graduated on time with their classmates. As online options and opportunities are being sought out for the students in following years, we can use this format as a foundation.

\section{Acknowledgements}

Special thanks to Kristen Wiiasanan, PharmD, for her contributions in the longitudinal COVID-19 drug information program.

\section{References}

Accreditation Council for Pharmacy Education Self-Assessment Instrument for the Professional Degree Program of Colleges and Schools of Pharmacy. (July 2016). Version 1.0. Retrieved from https://www.acpe-accredit.org/pdf/Rubric2016Guidelines1.0bUpdate2019.pdf

Badreldin, H. A., Alshaya, O, Saleh, K. B., \& Alshaya, A. (2020). Restructuring the Inpatient Advanced Pharmacy Practice Experience to Reduce the Risk of Contracting COVID-19: Lessons from Saudi Arabia. J Am Coll Clin Pharm, 3(4), 771-777. https://doi.org/10.1002/jac5.1237

CEImpact. (2020). Retrieved May 27, 2020 from https://www.ceimpact.com/

E-FORCSE. (2020). Electronic-Florida Online Reporting of Controlled Substance Evaluation. Retrieved 26 May, 2020 from http://www.florida.pmpaware.net.

Eiland, L. S., Staton, A. G., \& Stevenson, T. L. (2018). Providing an Academic APPE Elective via Videoconference between Off-campus Faculty and Students. Am J Pharm Educ, 82(8), 6645. https://doi.org/10.5688/ajpe6645

Florida Prescription Drug Monitoring Program AWARxE Requestor User Support Manual. (December 2018). Version 2.0. Apriss, Inc. $\quad$ Retrieved $\quad$ May $\quad 20, \quad 2020$ from https://d1b1sdx6nwlphm.cloudfront.net/aware/fl_aws_prod/narxcare_user_guide.pdf 
Fuller, K. A. Heldenbrand S. D., Smith M. D., \& Malcom D. R. (2020). A Paradigm Shift in US Experiential Pharmacy Education Accelerated by the COVID-19 Pandemic. Am J Pharm Educ, 84(6), 8149. https://doi.org/10.5688/ajpe8149

Mohammad, I., Berlie, H. D., Lipari, M., Martirosov, A. L., Duong, A. A., Faraj, M., Bacon, O., \& Garwood, C. L. (2020). Ambulatory Care Practice in the COVID-19 Era: Redesigning Clinical Services and Experiential Learning. J Am Coll Clin Pharm, 3(6), 1129-1137. https://doi.org/10.1002/jac5.1276

University of Florida. (2020). College of Pharmacy. Retrieved May 20, 2020 from https://covid.pharmacy.ufl.edu/

\section{Copyrights}

Copyright for this article is retained by the author(s), with first publication rights granted to the journal.

This is an open-access article distributed under the terms and conditions of the Creative Commons Attribution license (http://creativecommons.org/licenses/by/4.0/). 